\title{
Introduction: Interrogating Harm and Abuse: A Lifespan Approach
}

\author{
Alison Bowes* and Brigid Daniel** \\ Department of Applied Social Science, University of Stirling \\ *E-mail: a.m.bowes@stir.ac.uk \\ **E-mail: b.m.daniel@stir.ac.uk
}

\section{Background: researching harm and abuse}

At any time any person faces a possibility of suffering harm from another, and the broad criminal justice framework aims to provide a general level of protection from such harms to the whole population. However, possibilities of abuse, exploitation or neglect are conceptualised as more likely for certain people. These include those in intimate partner relationships, or those whose level of dependency on others is greater as a result of life stage or impairment. Specific legal and policy measures aim to address potential harm in such situations, and are proliferating.

For several decades, the general acceptance that the state in most developed countries has a legitimate role in protecting some potential victims of abuse, notably women and children, has been underpinned by an extensive legislative and bureaucratic framework. More recently, the focus of state concern has broadened to include people considered at heightened risk of harm due to impairment or older age. Evolving legislative and bureaucratic protective responses often parallel those already in place for children. Examples include the requirement in England and Wales by October 2001 for all local authorities to develop inter-agency adult protection procedures governing investigation of and responses to concerns about adult abuse; and in Scotland, the Adult Support and Protection (Scotland) Act 2007, provides measures to protect adults who are believed to be at risk of harm. These include rights of entry to places where adults are thought to be at risk of harm, a range of protection orders including assessment, removal of the adult at risk, and banning of the person causing the harm from contact with them; and supporting the creation of multi-disciplinary adult protection committees.

The evidence base for these policy developments, as well as for legislation on domestic violence and child abuse which preceded them, has been fragmented. Critical analysis has seldom moved beyond the boundaries of each, with diverse research streams. In the 1970s, recognition of 'family' violence as a social problem began to be acknowledged, but with a focus on a range of groups (including children, intimate female partners and older people); not surprisingly, research endeavours, practice responses and analysis likewise became fractured. The 1980s and 1990s saw the further development of separate strands of research on child abuse, domestic abuse and elder abuse, with abuse of other groups, such as adults with disabilities, significantly neglected. Whilst there are key conceptual developments in each area, there has been remarkably little cross-fertilization of ideas, with each field thus failing to learn from the insights of others. For example, state intervention for the protection of children in the UK has been informed since the 
1960s by developmental literature and research that emphasises the relative vulnerability of children and the negative impact of abuse and neglect upon developmental pathways (Howe, 2005). By contrast, concepts of protection in domestic abuse have been driven by a political analysis of power and gender (Stark, 2007). And in the field of learning disability, mental health and older people, the primary concepts for understanding abuse are those of dependence in the context of stress and the associated strained caring relationships (Forbat, 2005).

Despite the lack of comparative analysis, policy developments are apparently proceeding on the basis of uncritical transfer of practice between fields, increasing the potential for state intervention into the private sphere of citizens. For example, legislation and guidance for the protection of adults bear remarkable resemblance to those developed for child protection. And, increasingly, protection guidelines are being extended to 'child and adult' protection. However, solutions produced in this apparently simplistic way are, we contend, likely to be impoverished, due to a lack of appreciation of the complexity of the problems they address and the failure of debate in the separate strands of research to be mutually informative.

This themed section brings together researchers who have studied abuse and neglect in a variety of contexts, in an effort to open debate on mutual learning about these issues across the lifespan. They are drawn from presentations at an ESRC-funded seminar series at the University of Stirling, Scotland, entitled 'Interrogating "harm" and "abuse": protection and citizenship across the lifespan'. The seminars aimed to explore experiences of and responses to harm and abuse across the lifespan with a view to integrating insights from previously disparate fields and encouraging critical discussion of harm and abuse from a lifespan perspective. In this introduction, we consider the potential productivity of a lifespan approach, and identify some of the lessons emerging from this group of papers.

\section{What does a lifespan approach offer?}

Our premise is that adopting a lifespan approach can prompt different and more rounded understandings of harm and abuse and lead to more holistic policy and practice responses. The starting point for this is to explore the problem of harm and abuse from the point of view of experiences, both of 'victims' and perpetrators. Key concepts include constructions of 'harm' and 'abuse' as they vary across fields and across cultures; harm and abuse within interpersonal and intimate relationships; and the responses of victims and perpetrators, including exploration of agency and resilience as concepts which can be explored across fields of interest to develop more sophisticated understandings of the interpersonal dynamics of abuse. Interpersonal relationships and individual experiences need to be contextualised to explore different types of abuse and their construction (or non-construction) as social problems, and to examine 'cultural orders' (Boddy, 1998) and cultural contexts pertaining to 'victims', their recognition and construction.

With regard to understandings of abuse and harm, a lifespan approach encourages us to consider why, for example, violence within the context of an intimate partner relationship may be labelled as 'domestic abuse' in adulthood but 'elder abuse' in later life. Similarly, a disabled child whose needs are neglected can be responded to by child protection services throughout childhood, but be 'transferred' to an adult service and become subject to a whole different set of procedures the day they officially become an adult. Within the context of complex family relationships, Hogg et al. (2009) 
found many situations where individuals can simultaneously be viewed as 'victims' and 'perpetrators'; for example, where there are levels of mutual aggression between parents and adult offspring for whom they are caring. McCreadie (1996) points to similar complexities in cases of elder abuse. The complexities hint at the fact the people can move between different groups or socially constructed categories and can simultaneously occupy different categories. Therefore, theoretical frameworks for analysis and models for practice cannot rely on simple categorisation.

These papers therefore, each address the experiences of physical or emotional violence, considering them in relation to different socially constructed groupings of people. The papers focus mainly on studies and explorations of practice, as it is conducted within the current policy framework, with a view to identifying some core cross-cutting themes that can inform policy refinement and subsequent practice guidance. The papers critically analyse concepts of vulnerability and risk in relation to some core questions such as:

- How are 'harm' and 'abuse' constructed, and who is active in their construction?

- What are the key differences and similarities in experience of harm and abuse across the lifespan?

- In what ways are 'victims' constructed, recognised and 'authorised'?

- Are any social groups intrinsically vulnerable?

- How, and under what conditions, does 'harm' to a category of people move from a private concern to a social problem that requires a policy and practice response?

Two papers focus on the early stages of the lifespan - Daniel considers the category of 'child' and Williams that of 'teen'. Daniel's paper addresses issues in relation to the concept of child as victim; Williams also covers this, and overlays the additional category of 'prostitute' - thus adding new layers of understanding to the analysis of child as victim. Two papers focus on the latter stages of the lifespan - both Manthorpe and Bowes and Kelly focus on the category of 'older adult'. Manthorpe and Bowes discuss how ethnicity, age and other differentiating factors interact to affect experiences of and responses to mistreatment in older age. Kelly introduces the additional category of 'person with dementia' - thus again adding another layer to the analysis. Donovan and Hester focus not on a stage in the lifespan, as such, but on the category of 'victim' of domestic abuse. However, whilst a specific stage of the lifespan is not defined for this category, the implicit understanding underpinning practice models is of domestic abuse as a feature of adulthood and as distinct from 'child abuse' and 'elder abuse'. For the purposes of this themed section, therefore, this paper occupies the 'adult' part of the lifespan. It also provides a different lens through which to consider existing models of domestic abuse because it focuses on research with people in same sex relationships - thus introducing another socially constructed category for consideration. Finally, Johnson et al. review literature that addresses different stages of the lifespan and in relation to different 'groups' of people such as those who use mental health services or those with learning or physical disabilities.

We shall consider each paper in more detail and point to some cross-cutting themes and questions. We do not aim to produce an overarching 'theory of everything', rather we aim to use these papers as illustrations of the kind of questions that a lifespan approach can open up. We also do not wish to argue that the endeavour to protect people from harm is misguided. On the contrary, we are clear that any person who is being harmed 
or exploited by another must have access to appropriate and effective assistance. Our argument is that such assistance is likely to be more effective if based upon a holistic and nuanced understanding of harm and abuse and the complexities of the understandings of 'victim' and 'perpetrator', as well as avoiding some potential obstacles to support that may derive from a focus on lifestage rather than lifecourse.

\section{Child protection}

As Daniel points out, policy and legislation for the protection of children are wellestablished and have a long history in the UK. Against a backdrop of the kind of protections from harm and violence offered to all citizens by the civil and criminal law, the introduction of specific child protection legislation and attendant practice frameworks sets a marker for the separation of a particular category of person for particular attention and a specific set of differentiated responses. Precisely because they appear to be well established, child protection processes offer a beguiling model, once the spotlight of concern moves to pick out a different category or group of people. However, Daniel describes some of the ways in which the child protection system is problematic in its own right, let alone as a model for protection of other groups who may be labelled as vulnerable by public stories of concern. Further, the development of protective frameworks for different categories raises the question as to what needs to be different. This throws the spotlight back on the underlying assumptions about children within the child protection system. As Daniel asserts, this is based on the concept of childhood as inherently 'vulnerable' and signals that the state should adopt a particular role in overseeing children's safety and protection by virtue of their childhood. This is linked with what is viewed as the uniquely damaging impact of the interaction of maltreatment with developmental processes. Looking at this from a lifespan approach raises two issues. First, it suggests that maltreatment does not interact with developmental processes to the same damaging extent in later stages of the lifespan. Second, it reduces the focus on the immediacy of the impact on the child as a 'person' rather than a person in development or 'human becoming' (Qvortrup, 1994). This paper also introduces some of the ways in which the concept of 'victim', as ascribed to children as a category, overlooks the active role that children play in their lives and the ways in which they may develop their own coping strategies. Whilst the system is comfortable with the concept of child as 'victim' for the purposes of care and protection, once young people are perceived as a danger to others or threat to social order then they are moved from the category of child and constructed as dangerous youth.

Finally, this paper highlights the extent of individual differences in response to adversity. This raises the question as to whether the differences in response within a category such as 'child' are greater than the similarities. For example, could an individual child's response to abuse be more similar to an individual older person's response than that of another child of a similar age?

\section{Young people and sexwork}

Williams considers young people who survive by selling sex for money. Because these young people have developed strategies for survival that move them into 'adult' behaviours, they introduce ambiguity to the conceptualisation of childhood. Further, 
because these young people fall into a category of 'prostitute' they challenge social constructions of the 'child victim'. The young people are both 'victims' of the sex trade and yet are treated as 'perpetrators' by the legal system. And, at the same time, the individuals may resist the notion of themselves as 'victims'. The 'public story' (Jamieson, 1998) is, therefore, different from the private story.

Williams also brings us the voices of young people themselves who do not tend to use the language of 'harm'. Instead, they use the term 'hurt', which allows for a more visceral understanding of both the emotional and physical assaults they have experienced. Williams suggests that hurt implies a more enduring impact than harm, perhaps again because of the interaction with, and interruption of, developmental processes. These young people also articulately resist the adoption of the role or identity of victim. Instead, they provide narratives of 'survival'. Survival could be seen as an achievement even though the level is at a very low baseline. As far as they are able, these young people take charge of their own lives, thus demonstrating a form of resistance. Whether this resistance could also be characterised as 'resilience', as described by Daniel, could also be considered. Williams explores the implications of this for protective systems. The construction of young people as victims means that the attendant response is rescue something that state child protective services are comfortable with. However, if young people do not see themselves as victims, then they do not see themselves as in need of rescue. This can lead to a mismatch between needs and services and Williams suggests that to develop appropriate services, providers need to think of the prostituted teenagers not as helpless victims, but as survivors.

\section{Diversity in later life}

Manthorpe and Bowes' paper takes us to the latter stages of the lifespan with their consideration of elder abuse. Drawing lessons from two studies, the paper explores abuse and mistreatment of older people at individual and relationship levels and contextualises research findings within wider policy debates. The central emphasis of the paper is on diversity and its impact and implications, which are contrasted with the definitions of abuse and neglect enshrined within adult safeguarding policy. The themes of diversity and policy definition echo the critiques by Daniel, Donovan and Hester, Kelly and Williams of responses to mistreatment that adopt predefined assumptions about, and definitions of, experiences of abuse. Ethnicity as a form of diversity emerges as another factor that raises questions about how mistreatment is framed in policy and how responses to it may miss ways of effectively connecting with experience because consideration is not given to the views of those being mistreated.

The paper describes elder abuse as occurring in a wide variety of relationships, including spousal, other family, neighbourly and care worker relationships - thus signalling another set of cross-cutting issues. One study asked people to specify what they had experienced in the last year and found a prevalence rate for experiences that researchers and professionals defined. This study highlights the extent of neglect, which seems to be more common than active abuse. The figures in relation to the harm of children also suggest that neglect is more prevalent than other forms of abuse, and that it leads to some of the worst outcomes, whilst posing the greatest challenge to practitioners (Stevenson, 2007). This may be an example of where there may be some benefits to 
learning from the experience of the child protection system, which struggles to deal with long-standing situations because it is more geared up to deal with 'incidents' of abuse.

The second study focused on the experiences and views of minority ethnic groups concerning mistreatment of older people. These emerge as fundamentally influenced by lifetime social exclusion, which resulted in isolation of families from service access, lack of support for family carers of older people and lack of choice for older people who may need to seek support from outside the family. These findings clearly illustrate that elder abuse cannot be seen merely as a function of old age, but relates to much wider processes and requires address in policy beyond adult protection or safeguarding. Manthorpe and Bowes argue that human rights issues of racism and discrimination are also highly relevant here, suggesting that harm and abuse are issues that resonate far beyond the bounds of policy that aims specifically to address them.

\section{People with dementia}

Kelly introduces the model of the 'three selves' as a framework for analysing her observations of abuse within a locked ward for people with dementia. This raises interesting questions about what is needed for someone to be accorded humanity. It also poses the question as to whether the same framework could be applied to all stages of the lifespan, including childhood. One of the key messages from this paper is the importance of the interaction between patients and staff - the harm emanates from the lack of validation of self and the damaging impact of lack of recognition of self. In relation to children, Howe et al. (1999) have described the impact upon the development of views of the self and views of others of damaging carer and child interactions. Howe et al. are writing very much from a child development perspective and link the extent of harm to the impact of negative interactions upon development of secure attachment. However, the model of the three selves provides an additional and complementary way of understanding the impact of damaging interactions at any stage of the lifespan.

Kelly also draws links with child development literature to explore patterns of actionreaction and ways in which behaviour can be reinforced by staff responses. She shows that the terms of interactions are set by the staff who seem to draw on assumptions about people with dementia, rather than engaging with people with dementia as individuals. Equally one could ask whether people working in many residential settings are also victims of a system that devalues the work they do and provides little support or resources for more empathic and creative practice. There are parallels with the lack of engagement by services with the teenagers in Williams' study. Kelly, therefore, is touching on the theme of relationships - here the relationships between staff and patients. The study suggests that policy and practice frameworks need to be able to incorporate attention to human interactions and relationships in order to grapple fully with the complexity of what may be considered abuse.

The people in the locked ward that Kelly observed also have 'public stories' - they are clearly socially constructed as being difficult or having so-called 'challenging' behaviour which is an attribute of them - not a product of the damaging interactions and challenging circumstances within which they live. Kelly describes how people, even within these very constrained circumstances, show 'resistance' to passive 'victim' status. Again, we can ask whether this resistance is a form of resilience. Overall, what Kelly's paper shows is that, although the patients in the wards could potentially fall into a category of concern 
because they have dementia, they may instead be placed into the category of 'troublemaker'. Again, there are parallels here with the ways in which systems struggle to deal with 'troublesome' children in an empathic way.

\section{Same sex relationships}

It is in Donovan and Hester's paper that the theme of rejection of the term victim is most overt. By giving voice to the 'victims' of domestic abuse within same sex relationships they open up a range of private stories that clearly challenge the public discourses of domestic abuse. The study participants did see themselves as abused, but described an unfolding process of recognition. The paper shows the importance of subjectivity - it suggests that those experiencing violence, which they slowly come to recognise as such, are initially misled in some way by dominant 'public stories', which include some about the nature of domestic violence and others about love. Like Williams, Donovan and Hester focus on the active attempts by 'victims' to take charge of things by trying to look after the 'perpetrator' and putting things right for them.

This rejection of the label of victim may not be exclusive to those in same sex relationships - but the study of this group allows existing theories of understanding violence within the context of intimate partner relationships to be challenged. The dominant discourse on domestic abuse depends on the heterosexuality of the relationship and a gendered construction of the 'victim' as passive/weak. Such a view may prevent recognition of domestic violence by those in same sex relationships. Donovan and Hester's feminist analysis emphasises issues of power and control rather than a focus on physically violent incidents and thus allows for a more inclusive understanding of who may experience domestic violence, including behaviours other than physical violence. This paper, therefore, demonstrates the value of looking at a situation through the perspective of a different lens or group experience.

Donovan and Hester's focus on love - under-researched in the domestic violence field, despite being one of the reasons most commonly given by heterosexual women for remaining with a violent partner - enables them to unpack how and why the notion of victim is resisted. Explanations built around love could well then be applied back to the heterosexual experience to allow for more holistic explanations. Further, the role of love and attachment both in intimate partner relationships as well as in parent/child and carer/caree relationships should be considered as helping to explain the complexity and ambiguity of the situations. Together these issues reassert the importance of considering circumstances of harm and abuse within the context of the relationships whether between partners as described here, or between practitioners and users of services, as described in Kelly's paper.

\section{A lifespan approach}

Johnson et al. set out the parameters for a life-span approach, which they suggest can be adopted on macro and micro levels. At a macro level, the concept of 'lifespan' can be applied as a concept that helps to move us away from placing people into categories of concern. On a micro level, it encourages us to consider continuities and discontinuities in an individual's experience and in their circumstances, in particular around re-victimisation. From the literature they identify examples of both and explore 
the importance of understanding continuities in people's experiences. Johnson et al. encourage us to look at ways in which different aspects of the lifespan as an abstract concept have been researched and theorised and to consider why different lenses have been used to examine different stages of the lifespan and different conditions.

Their analysis has are clear implications for practice. If service delivery requires that people be placed within particular boxes for concern, labelled 'child', elder', 'disabled' and so on, then when people do not fit the boxes or when they need to be moved from box to box, service delivery becomes fragmented and inconsistent. This raises the question as to whether we need principles to guide practice rather than building guidance and protocols premised upon specific and narrow characterisations of the nature of the problem. Common to all the papers is the mismatch between how people define themselves and the 'public stories' about the category or group they happen to be in when encountering services. The concept of resilience also reinforces the need to take a far more nuanced approach to assumptions about the routes from adversity to harm.

\section{Conclusions}

Taking a lifespan approach, therefore, opens up some intriguing questions as to whether there are some universal themes that transcend specific circumstances and 'group' membership. The papers in this themed edition begin to point towards some areas for further exploration when developing and refining 'protection' or 'safeguarding' policy. One theme that cuts across the papers is rejection, resistance or re-framing of the role of 'victim'. This may be more explicit in some 'groups' and, in fact, articulated directly as such. In others, including young children and people with dementia, this may be shown more implicitly through behaviour. Another emergent theme is that of a mis-match between the complexity of people's circumstances and the apparent need for services to be delivered within the context of labelled categories, which lack sensitivity to diversities that influence people's experiences, their access to services and the services they may (or may not) receive. In addition, the relationship context provides the backdrop for explaining why categories may be too restrictive. The fluid and interactive nature of relationships within and between generations and across the lifespan often blur simple distinctions between victim and perpetrator and affect the ways in which people conceptualise their own situation. And, finally, the specificity and specialism of protection/safeguarding policies are called into question by the wider impacts of status (e.g. the child or older person as lacking power) and social exclusion and discrimination (e.g. as manifested in sexism, heterosexism, ageism or racism).

The lifespan approach, therefore, highlights some of the underlying, and often unidentified, assumptions of policy and practice models. For example, that there is a distinct set of legislation in relation to the abuse of children becomes more apparent when it is decided that a further distinct set of legislation may be required for older people. This raises questions about whether 'protection' is provided in the context of the social category into which a person is considered to be located, or whether 'protection' may be better addressed in relation to a basic set of human rights, to a life free from harm. As the categories about which the state assumes some responsibility for protection proliferate, then we are forced to inquire as to what exactly are the distinctive aspects of each category, that point to the need for different forms of protection. 
The papers presented here provide evidence and arguments against categorising people purely on the basis of their age, gender, sexuality, ethnicity as a basis for the design of protection policy. They suggest that new lenses for conceptualising harm, abuse and protection are needed.

\section{References}

Boddy, J. (1998), 'Violence embodied? Circumcision, gender politics and cultural aesthetics', in R. E. Dobash and R. P. Dobash (eds.), Rethinking Violence Against Women, Thousand Oaks: Sage.

Forbat, L. (2005), Talking About Care: Two Sides to the Story, Bristol: Policy Press.

Hogg, J., Johnson, F., Daniel, B. and Ferguson, A. (2009), 'Interagency collaboration in adult support and protection in scotland: processes and barriers', Final Report, Dundee University, Dundee.

Howe, D., Brandon, M., Hinings, D. and Schofield, G. (1999), Attachment Theory, Child Maltreatment and Family Support, Hampshire: Palgrave.

Howe, D. (2005), Child Abuse and Neglect: Attachment, Development and Intervention, Houndmills: Palgrave Macmillan.

Jamieson, L. (1998), Intimacy: Personal Relationships in Modern Society, Cambridge: Polity Press.

McCreadie, C. (1996), Elder Abuse - Update on Research, London: Age Concern and Institute of Gerontology, King's College.

Qvortrup, J. (1994), 'Childhood matters: an introduction', in J. Qvortrup, M. Bardy, G. Sgritta and H. Wintersberger (eds.), Childhood Matters: Social Theory, Practice and Politics, Aldershot: Avebury.

Stark, E. (2007), Coercive Control: The Entrapment of Women in Personal Life, Oxford: Oxford University Press.

Stevenson, O. (2007), Neglected Children and Their Families, Oxford: Blackwell Publishing. 